\title{
Case of stillbirth due to infection with Listeria monocytogenes
}

\author{
A. BECK, P. K. O'BRIEN, AND V. F. MACKENZIE
}

From Paddington General Hospital, London

SYNOPSIS A case of listeriosis in a stillborn baby is described. The causative organism was isolated from lung, placenta, and meconium. The only manifestation of infection of the baby's mother was a slight pyrexia three days before delivery which subsided quickly after treatment with ampicillin. Examination of the mother 11 days after delivery failed to produce evidence of listerial infection.

In 1951 the German workers Reiss, Potel, and Krebs described a condition of the foetus and newborn infant characterized by generalized miliary focal granulomas in many organs for which they proposed the name 'granulomatosis infantiseptica'. Potel (1951) isolated from the lesions a Gram-positive bacillus which was later identified by Seeliger (1952) as Listeria monocytogenes. Since then similar cases have been reported in a number of countries in Europe, America, and Australia.

In Britain, Barber and Okubadejo (1965) were the first to describe a case of proved transmission of Listeria monocytogenes from a mother to her infant who died within a few hours of birth. Since then Jellard and Churcher (1965) have reported another similar case.

In view of the apparent rarity in this country of stillbirths due to this infection the following case is presented.

\section{CASE REPORT}

A 31-year-old West Indian living in this country for six years had a previous obstetric history which included two full-term deliveries in St. Lucia in 1954 and 1957. The first child is alive and well. The second died at $1 \frac{1}{2}$ years of age from 'an infection'.

Her third pregnancy was supervised in this hospital in 1962. Progress throughout was uneventful and she was admitted in labour at term, the membranes having ruptured 10 hours previously. A few hours after admission she developed a temperature of $101^{\circ} \mathrm{F}$. $\left(38 \cdot 3^{\circ} \mathrm{C}\right.$.); treatment with penicillin and streptomycin was commenced and the pyrexia subsided. After a long and inert labour foetal distress developed. A fresh stillborn male infant weighing $7 \mathrm{lb}$. was delivered by forceps 70 hours after the onset of labour. Post-mortem examination showed widespread pyogenic pneumonia. Cervical swabs Received for publication 17 May 1966. taken from the mother during labour yielded a growth of coliforms and Gram-positive cocci. The puerperium was uneventful.

Her present pregnancy progressed normally until the thirty-sixth week, when she suffered some lower abdominal pain for which no cause was found. She was apyrexial. Urine examination at the time was negative. She was admitted with a few contractions at the thirtyninth week. The membranes were intact. There was a pyrexia of $99 \cdot 6^{\circ} \mathrm{F}$. $\left(37 \cdot 5^{\circ} \mathrm{C}\right.$.) and a marked tachycardia. Clinical examination did not reveal a cause for these findings. Urine examination including culture was negative. A blood count gave the following results: haemoglobin 14.0 g. $/ 100 \mathrm{ml}$., W.B.C. 12,000 per c.mm. $(65 \%$ neutrophils, $8 \%$ eosinophils, $24 \%$ lymphocytes, $3 \%$ monocytes). No malarial parasites or filariae were seen. No ova or cysts were present in the faeces.

Forty-eight hours after admission the membranes ruptured suddenly. The liquor amnii was heavily stained with meconium. At this stage no foetal heart sounds were audible, although up till then they had been regular. A syntocinon infusion was set up, and 14 hours later a stillborn male infant weighing $3,245 \mathrm{~g}$. was delivered. The puerperium was normal.

\section{POST-MORTEM FINDINGS}

The baby weighed $3,245 \mathrm{~g}$. and was macerated. Claret-coloured effusions were present in all serous cavities. The pleural aspects of the lungs showed multiple petechial haemorrhages and the cut surface showed numerous small whitish foci which, on presure, exuded a white sticky fluid (Fig. 1). The spleen was slightly enlarged. No other naked-eye abnormality was noted.

On microscopical examination, in addition to degenerative changes, the liver showed several rounded necrotic foci containing nuclear debris, surrounded by mononuclear cells (Fig. 2). 


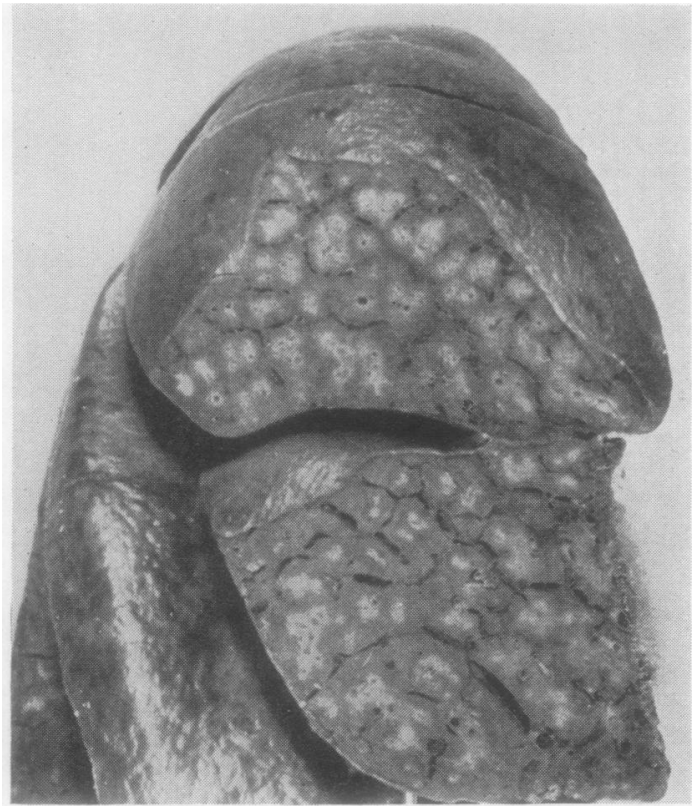

FIG. 1. Multiple granulomata in baby's lung.

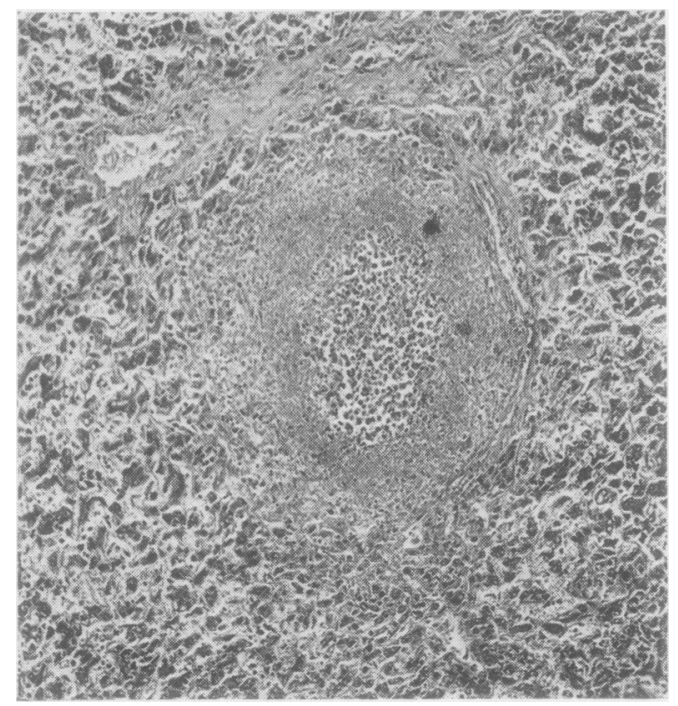

FIG. 2. Granuloma in baby's liver (haematoxylin-eosin $\times$ 90).

The reticulin pattern was destroyed and Grampositive bacilli were present in these areas. Similar abscesses were found in the spleen.

Microscopically the lungs showed a severe bronchopneumonia. There was hypertrophy of mucous glands and much mucin was present in and V.F. Mackenzie
alveolar ducts. Granulomata similar to those in the $\stackrel{\frac{0}{\overrightarrow{0}}}{\text { lo }}$
liver were seen, some in a parabronchial position. The alveolar exudate was composed mainly of $\stackrel{\text { ? }}{?}$ mononuclear cells, which were also present in the alveolar walls.

The placenta weighed $600 \mathrm{~g}$. and showed no naked- $\frac{\bar{\sigma}}{\overline{9}}$ eye abnormality apart from an occasional white $\varnothing$ infarct. Microscopically, inflammatory foci com- ® posed of mononuclear cells were seen in intervillous $\vec{\circ}$ spaces. Organisms were not identified on section and $\rightarrow$ there was no inflammatory reaction in the cord.

Swabs of lung and meconium and a suspension of placental tissue ground up in saline were cultured ? aerobically and anaerobically on blood agar; all $\overrightarrow{0}$ cultures yielded a profuse, sometimes pure, growth of Listeria monocytogenes after overnight incubation. of Characteristic Gram-positive bacilli were seen in large numbers in direct films of meconium and very occasionally in films of placental tissue.

\section{DESCRIPTION OF ORGANISM}

MORPHOLOGY AND CULTURAL APPEARANCE The organism was a short Gram-positive bacillus of medium thickness with no characteristic arrange- $\mathscr{\mathscr { C }}$ ment in the Gram film. It grew at room temperature and slightly better at $37^{\circ} \mathrm{C}$., and showed a tumbling motility when grown at room temperature. Colonies on blood agar were smooth, semi-transparent, with an entire edge and were surrounded by a narrow

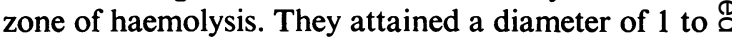
$2 \mathrm{~mm}$. after 48 hours' incubation. Growth in broth was diffuse.

BIOCHEMICAL CHARACTERISTICS The organism produced in 24 hours acid without gas in glucose, laevulose, maltose, rhamnose, and trehalose. There? was late acid formation (three to 20 days) in glycerol, 윽 inulin, lactose, mannite, sucrose, salicin, and sorbitol. There was no reaction in adonitol, arabinose, dextrin, dulcitol, inositol, raffinose, and xylose. It produced catalase but not oxidase, was methyl-red positive and Voges-Proskauer negative; it split $\rightarrow$ aesculin and did not liquify gelatin; it was indole, urease, and $\mathrm{H}_{2} \mathrm{~S}$ negative, and did not utilize citrate. It grew on McConkey agar, Hoyle's tellurite agar, and in $7 \%$ salt broth.

SENSITIVITY TO ANTIBIOTICS It was sensitive in disc tests to the following drugs: penicillin ( $0 \cdot 1$ unit), streptomycin $(6 \mu \mathrm{g}$.$) , chloramphenicol (8 \mu \mathrm{g}$.$) ,$ tetracycline (3 $\mu \mathrm{g}$.), erythromycin $(0 \cdot 2 \mu \mathrm{g}$.), ampicil. $\stackrel{?}{+}$ lin $(2 \mu \mathrm{g}$.$) , ceporin (5 \mu \mathrm{g}$.$) , neomycin \left(10 \mu \mathrm{g}\right.$.), and ${ }^{0}$ sulphafurazole $(40 \mu \mathrm{g}$.$) .$

PATHOGENICITY Four mice, two of which had been $\overline{8}$ inoculated intraperitoneally and two injected sub- 
cutaneously with $0.3 \mathrm{ml}$. of a 1:10 dilution of an overnight broth culture, died four to nine days after the injection. At necropsy numerous scattered whitish nodules of pin point to pin head size were seen in the liver, spleen, and pericardium. On section these nodules were found to consist of areas of necrosis and infiltration with mononuclear cells, polymorphonuclear leucocytes, and some nuclear debris. The lungs were congested and showed evidence of sero-fibrinous pleurisy. Gram stain of sections revealed masses of Gram-positive organisms, especially in the liver and the pleura, and cultures of these organs and of the spleen produced heavy growth of Listeria monocytogenes. The kidneys showed only scanty minimal lesions on histological examination.

Instillation of one drop of a 1:10 dilution of an overnight broth culture into the conjunctival sac of a guinea-pig produced an intensive kerato-conjunctivitis which after 48 hours became purulent and was followed by the formation of a dense corneal pannus.

\section{DISCUSSION}

In contrast to the severity and bad prognosis of neonatal listeriosis the concomitant infection of mothers of affected babies is usually very mild or altogether symptomless (Seeliger, 1961). In the present case the only manifestation of infection of the mother was a slight pyrexia which developed three days before her delivery and which responded quickly to ampicillin treatment. Cultures of the mother's cervix, vagina, and urine, taken 11 days after delivery, were negative for Listeria. Serum obtained at the same time agglutinated an ' $O$ ' suspension of the baby's organism in a dilution of 1:40 whilst failing to agglutinate an ' $H$ ' suspension in a dilution of $1: 5$. This finding is not of diagnostic significance as about one third of sera taken from healthy controls contain Listeria agglutinins up to a titre of $1: 160$ (Seeliger, 1961). It is likely that these negative findings resulted from the prompt antibiotic treatment of the mother. This was, however, too late to influence the outcome of the baby's illness.

The origin and mode of the mother's infection is not known. There was no history of contact with farm animals or pets since the patient's arrival in this country six years ago nor did the patient recollect having consumed raw milk or raw meat during this time. There are only a few reports in the literature in which the mode of transmission of Listeria from animals or their products to men has been established.

In view of the known association of chronic listerial infection with habitual abortion (Rappaport, Rabinovitz, Toaff, and Krochik, 1960; Dungal, 1961; Toaff, Krochik, and Rabinovitz, 1962), it is tempting to speculate whether the previous stillbirth of our patient was due to the same cause as her present one. A re-examination, including Gramstaining, of the sections of lung of the first stillborn baby does not support this assumption.

Although it is possible that cases of foetal or neonatal listeriosis may occasionally have been overlooked it would appear that this manifestation of listerial infection is rare in Britain. In this hospital during the last four years a systematic search for this organism has been made in stillborn infants without success before the present case.

We wish to thank Mr. A. C. Fraser, M.R.C.O.G., under whose care the patient was admitted, for permission to publish this case.

\section{REFERENCES}

Barber, M., and Okubadejo, O. A. (1965). Brit. med. J., 21, 735. Dungal, N. (1961). Lancet, 2, 513.

Jellard, G. H., and Churcher, G. M. (1965). Brit. med. J., 2, 878.

Potel, J. (1951). Zbl. Bakt., I. Abt. Orig., 156, 490.

Rappaport, F., Rabinovitz, M., Toaff, R., and Krochik, N. (1960). Lancet, 1, 1273.

Reiss, H. J., Potel, J., and Krebs, A. (1951). Z. ges. inn. Med., 6, 451. Seeliger, H. P. R. (1952). Dtsch. med. Wschr., 77, 587.

(1961). Listeriosis, pp. 154 and 228. Karger, Basle and New York.

Toaff, R., Krochik, N., and Rabinovitz, M. (1962). Lancet, 2, 482. 